\title{
LA PESTE BUBÓNICA EN EL PUERTO DE ARICA $(1903-1928)^{*}$
}

\author{
THE BUBONIC PLAGUE IN THE PORT OF ARICA \\ (1903-1928)
}

Pablo Chávez Zúñiga**

\begin{abstract}
En este artículo se analiza el desarrollo de sucesivos brotes de peste bubónica como problema de salubridad en el puerto de Arica entre 1903 y 1928, con el objetivo de profundizar en las respuestas político-médicas locales respecto de la epidemia. Este trabajo abarca el período que va desde la llegada de los primeros brotes a las regiones del norte de Chile hasta el descubrimiento de los antibióticos, los que resultaron decisivos para la reducción de la enfermedad. Mediante la perspectiva de la historia cultural de la medicina se abordan varias fuentes históricas, entre ellas, la prensa, bibliografía, literatura especializada y documentos del Archivo Histórico Vicente Dagnino. A partir de esa base se destaca la constitución de la Estación Sanitaria, la acción del lazareto, las actividades de los médicos en la ciudad, las políticas de higienización y el impacto de la peste en la zona de los valles. Por último, se estudia la relevancia de los avances farmacológicos y los progresos en la salubridad pública como elementos fundamentales en las mejoras de la calidad de vida.
\end{abstract}

Palabras claves: Peste bubónica, enfermedades, medicina, salubridad, Arica.

This article analyzes the development of successive outbreaks of bubonic plague as a health problem in the port of Arica between 1903 and 1928, with the aim of deepening local political-medical responses to the epidemic. This work covers the period from the arrival of the first outbreaks in the northern regions of Chile to the discovery of antibiotics, which were decisive in reducing the disease. Through the perspective of the cultural history of medicine, various historical sources are addressed, including the press, bibliography, specialized literature and documents from the Vicente Dagnino Historical Archive. From this base, the constitution of the Sanitary Station, the action of the lazareto, the activities of the doctors in the city, the sanitation policies and the impact of the plague in the area of the valleys stand out. Finally, the relevance of pharmacological advances and progress in public health are studied as fundamental elements in improving quality of life.

Key words: Bubonic plague, diseases, medicine, health, Arica.

\section{Introducción}

Ars longa vita brevis es una antigua cita de Hipócrates, médico griego considerado el padre de la medicina. Esta frase sintetiza el trabajo del historiador tratando de encontrar respuestas y abriendo nuevas interrogantes, en este caso diseñando el camino a una de las tantas enfermedades que marcó el devenir del puerto de Arica. En su calidad de espacio vital para el tráfico comercial desde tiempos coloniales, rico en historias por contar y que lleva a dedicar estas páginas a estudiar el escenario que construyó la peste bubónica en la localidad.

Esta enfermedad es una infección originada por la bacteria Yersinia pestis. Microorganismo que fue aislado por Alexandre Yersin, bacteriólogo del Instituto Pasteur de París (Pedroso 2010: 364). Se halla presente de modo natural en las ratas, en este caso una pulga actuaba como vector desde el roedor al ser humano. Por ello, El Ferrocarril denunciaba los riesgos de este insecto, al ser "difícil que exista otro lugar en la costa de Chile. En donde haya más pulgas que en Arica" (El Ferrocarril 26 de agosto de 1909). A su vez, una localidad portuaria se transformaba en el sitio indicado para el desarrollo del mamífero. En este período, el lazo que unía a la localidad con la economía mundial originaba las condiciones para un potente comercio, lo que profundizaba el intercambio desde lugares en que la peste era endémica (Cueto 2000: 31).

En la segunda mitad del siglo XIX, los descubrimientos de Louis Pasteur significaron una revolución con la irrupción del paradigma bacteriológico, determinando que los microorganismos

\footnotetext{
* Resultados de la tesis doctoral "Esa diaria gotera de la muerte: mortalidad infantil en Santiago (1860-1914)", perteneciente al programa de Doctorado en Historia en la Universidad de Chile.

** Universidad de Chile. Santiago, Chile. Correo electrónico: pablo.chavez.zuniga@gmail.com
} 
son los causantes de varias enfermedades. Hasta ese momento, según la teoría miasmática, las afecciones eran originadas por elementos ambientales como las emanaciones fétidas del suelo y las aguas nocivas. En ese marco, a inicios de la nueva centuria, los planteamientos científicos mostraban una transición gradual entre ambas visiones, dejando establecido que la peste se originaba por microorganismos, pero las condiciones climáticas tenían gran influencia en la aparición de los brotes. El germen de la afección requería una temperatura promedio de 20 a $25{ }^{\circ} \mathrm{C}$ y una humedad relativa del $60 \%$, o sea el clima presente en la zona norte de Chile. De acuerdo con los conocimientos de la época, "este factor se relaciona en particular con los agentes transmisores de la infección y, sobre todo, con las pulgas infectantes, que no se desarrollarían bien en otro tipo de clima" (Gallinatto 1930: 37). Sumado a ello, los puertos del norte presentaban características sanitarias deficientes, lo que generaba un espacio apropiado para que la peste se transformara en endémica.

Los procesos de construcción nacional y los conflictos que se produjeron en las ciudades de Arica y Tacna tras la Guerra del Pacífico, han sido tratados de manera profunda por investigaciones en los últimos años (Galdames y Díaz 2007; Díaz, Galdames y Ruz 2010). Lo anterior se repite en los trabajos que abordan las dinámicas de la modernización en el norte del país (González 1995). Por su parte, las propuestas historiográficas acerca de la salubridad han aportado a los relatos nacionales o la zona centro sur del país (Salinas 1983; Illanes 1993, 2002; Zárate 2008; López y Beltrán 2013). Además, en otras áreas del continente se ha analizado la llegada de brotes epidémicos en localidades portuarias y las acciones que emprendieron las autoridades para mitigar sus consecuencias (Márquez 2001; Chase 2003; Ramacciotti 2006; Armus 2007; Rabelo 2013). Todas estas contribuciones han ampliado el espacio historiográfico, tanto en el norte del país como en el ámbito de la salubridad, en ese marco este trabajo pretende colaborar con algunas respuestas y generar nuevas interrogantes.

Investigadores nacionales han aportado a la historia de la salud, siendo una referencia los estudios de la peste bubónica. Los análisis desde la historia social han subrayado las experiencias de pobreza, marginalidad y exclusión de las personas. Refiriéndose a las condiciones de vida de los sectores populares de Iquique, el historiador Damián Lo Chávez profundiza la implementación de políticas sanitarias, los vínculos de la peste con la mortandad y los efectos del brote pestoso en la ciudad (Lo Chávez 2015). Josefina Cabrera, por su parte, distingue que el Estado invirtió gran cantidad de recursos para frenar la epidemia en Iquique, debido a su importancia económica como principal puerto salitrero, lo que se tradujo en ciertas medidas profilácticas (Cabrera 2004).

El artículo se encuentra respaldado en la información de los diarios El Morro de Arica (1890 - 1911) y El Ferrocarril (1907-1932), los que desarrollaron la trayectoria de la peste. Ambos, bajo la esfera ideológica del liberalismo, reforzaban la idea del crecimiento económico, comercial y progreso en la ciudad. El primero de los periódicos, en su década inicial, adoptó una perspectiva noticiosa relacionada con el nacionalismo peruano, lo que impulsaba su crítica hacia el manejo sanitario de la Junta de Beneficencia chilena o al Consejo de Higiene. No obstante, las publicaciones al momento de aparecer la bubónica, solo dedicaron sus páginas a entregar descripciones pormenorizadas del flagelo. Es posible indicar que nuestro centro de análisis es Arica, pero los periódicos también cubrieron lo que ocurrió, en los brotes de 1903-1905, en los puertos de Iquique, Pisagua y Mollendo.

El propósito de este artículo consiste en discutir acerca de un espacio poco estudiado por la historia de la salud en Chile e intenta aportar un relato de las enfermedades en el puerto de Arica, al centrar el análisis menos en la aplicación de las políticas de sanidad pública nacionales y más en el relato local de la salud, examinada desde la óptica de la larga duración. En ese marco, la investigación da cuenta de los planteamientos que realizaron diversos actores desde los albores del problema, pasando por diferentes etapas, hasta legitimar tratamientos de las enfermedades. Dicho ejercicio profundiza la imagen de una medicina que no solo tiene avances constantes, sino que se aplicaba en espacios precarios y que muchas veces generaba resistencias entre los habitantes. Esta propuesta temporalmente se aproxima a la etapa que se originaron los brotes iniciales de la epidemia en los puertos del norte de Chile a inicios del siglo XX y termina con el desarrollo científico de los antibióticos, siendo esto un factor clave para la erradicación de la enfermedad.

Con esta finalidad, la publicación se organiza en cuatro secciones: en la primera se exploran las características portuarias como espacios de propagación de enfermedades; en la segunda se indagan 
las medidas tomadas por las autoridades políticas, el funcionamiento de las instituciones dedicadas al ámbito de la salubridad y la conformación de la frontera norte como barrera sanitaria; en la tercera se estudian las descripciones médicas pertinentes a la peste y los tratamientos empleados en los enfermos; por último, se tratan los reglamentos y las normas empleadas en los fallecidos por esta peste.

\section{La peste en el puerto}

El seguimiento de los vínculos internacionales de las enfermedades revela los efectos y las medidas que se tomaron para mitigarlas en distintas localidades. El brote que afectó a las provincias del norte de Chile apareció en 1893 en el valle de Yünnam, en el sur de China, llevada por caravanas de comerciantes y por vía fluvial llegó al año siguiente a Cantón y desde ahí saltó al puerto de Hong Kong (Echenberg 2010: 16-46). Posteriormente, en 1899 se produjeron los primeros casos de peste en América, arribó a Paraguay y Argentina. Así, "como una amenaza constante, ha invadido por asaltos escalonados, desde 1901 a 1903, las costas occidentales del continente: San Francisco, Mazatlán, El Callao i, como última etapa, Iquique i Valparaíso" (Del Río 1904: 4-5).

Se trata de una relación entre los puertos de la región, marcada por el intercambio de bienes, tecnologías y que, en este caso, se transformaba en canal de propagación de enfermedades. Según la Dirección de Salubridad a inicios del siglo XX, la peste bubónica en los puertos de la zona norte del país había generado brotes epidémicos y no fue erradicada, convirtiéndose en una enfermedad endémica que azotaba anualmente a las comunidades. De acuerdo con las cifras presentadas por Gallinatto (1930: 29), entre 1908 y 1911, en Arica ocurrieron 230 casos de infección y 63 defunciones. Si bien la mortandad podría parecer baja, la peste tuvo múltiples impactos a nivel social y en la vida cotidiana de la población.

Los puertos del norte han sido escenario de muchas crisis producidas como resultado de las enfermedades. Las condiciones del comercio marítimo favorecían el contacto entre naciones, "ya que el vapor acorta las distancias i aproxima los países" (Murillo 1886: 4). Sin embargo, estos movimientos podrían ocasionar la propagación de contagios. Para regular esta situación, la Ley de Policía Sanitaria, en caso de la declaración de una epidemia contagiosa en un país extranjero, entregaba al Presidente de la República la potestad de "cerrar los puertos marítimos y terrestres, o someter a cuarentena y a medidas de desinfección a las naves, personas y cargas procedentes de países infectados. También podrá establecer cordones sanitarios que impidan en lo absoluto el ingreso de personas" (Oficina Central de Estadísticas 1896).

Para afrontar los brotes epidémicos, enmarcado en el proceso de modernización, las legislaciones ampliaron y profundizaron el poder político en el ámbito de salubridad. Por ejemplo, el doctor Adolfo Murillo (1886: 7-9), a raíz del agresivo brote de cólera asiático en 1886 en Argentina, indicaba que el gobierno chileno decidió cerrar las fronteras ante la amenaza. A pesar de la percepción de aislamiento e inmunidad que generaba la clausura vecinal, significaba solo el retardo para que el mal arribara al territorio. Según del médico Federico Puga Borne, los individuos tenían creencias mitigadoras frente a las enfermedades basadas en que:

\begin{abstract}
"Todavía no hai peligro, las precauciones son superfluas, la epidemia es un fantasma; esa misma es la que induce a engañarse sobre la naturaleza de los primeros casos de cólera que aparecen en cada pueblo, haciéndolos tomar como enfermedades inocentes" (Puga Borne 1886: 4).
\end{abstract}

A consecuencia de la formación de complejas cadenas de comercio marítimo, la epidemia adquirió caracteres de pandemia, afectando profundamente a varias naciones. La Convención Sanitaria de Washington (1902) fue la primera reunión a nivel panamericano en materia de salubridad, siendo un antecedente de la futura Organización Panamericana de la Salud (Cueto 2004: 39-41). Entre sus resultados, se fundó la Oficina Sanitaria Internacional, cuyo propósito era proteger la salud pública de los países, colaborar en el saneamiento de los puertos y fortalecer el tráfico de ultramar de los Estados miembros. En el caso de Chile, el gobierno financió un edificio para el funcionamiento de la Estación Sanitaria en Arica con el fin de organizar una barrera sanitaria para prevenir el ingreso de epidemias al territorio, mediante la inspección de los barcos en tránsito por este puerto y "no dejar pasar al sur ningún buque que vaya contaminado por una enfermedad que puede convertirse en epidemia en el país, como por ejemplo, la peste bubónica" (La Aurora 25 de diciembre de 1917). El médico 
Conrado Ríos estaba a cargo de la dirección de la institución, la que contaba con un laboratorio que permitía realizar estudios de las enfermedades endémicas regionales. Si algún vapor era considerado contaminado o infectado, se impedía su ingreso al país y era puesto en cuarentena, método que tenía sus raíces a finales de la Edad Media, cuando la administración del puerto de Venecia ante la inminencia de un brote pestoso, decidió aplicar un control a las embarcaciones, a lo que se agregaba la vigilancia a los infectados, la protección a los sanos y disposiciones especiales a los funerales, todo ello para frenar la capacidad de contagio del mal (Delgado, Estrella y Navarro 1999: 351).

Se recomendaba prolijidad en la desinfección de vapores procedentes desde varios puertos de la región. Las autoridades políticas desplegadas en el continente informaban al gobierno acerca de las pésimas condiciones de salubridad en muchos lugares del continente, donde la peste bubónica actuaba de forma endémica. Además, se relataban los estragos que causaban otras enfermedades, como la fiebre amarilla y la tuberculosis. A pesar de la rigurosa limpieza que se hacía en los puertos peruanos de Paita, Eten, Callao, Mollendo e Ilo, las zonas costeras del norte de Chile se encontraban expuestas a múltiples enfermedades, ya que al "desratizar los buques no se alejan los peligros de peste bubónica, la mayoría de la costa peruana está infestada por este mal" (El Ferrocarril 24 de enero de 1913).

\section{Acciones de la autoridad política-médica frente a la peste}

El crecimiento demográfico de la ciudad de Arica, a inicios del siglo XX, causó la concentración y el hacinamiento de población, lo que formaba un entorno preciso para la difusión de enfermedades (Dirección General de Estadística, 1930: 41). Los conventillos por su estado de insalubridad eran un peligro en los individuos, "verdaderas pocilgas, un sistema de extracción de basuras y aguas sucias deficientes, excelente para repartir a los cuatro vientos todos los microbios habidos" (El Ferrocarril 1 de abril de 1912). Además, el aprovisionamiento de agua potable era precario, no solo por la escasez propia de una localidad desértica, sino que, en muchos sectores, se realizaba a tajo abierto y acequias, desde ahí las personas se abastecían para su bebida. La falta de servicios de desagüe se expresaba en que "al lado de los pozos para escusados, se cavan pozos para extraer de ellos el agua que bebemos" (El Ferrocarril 13 de abril de 1912). Las autoridades locales estaban encargadas de atender la salubridad urbana mediante varias acciones, así como inspecciones de viviendas, distribución de agua y recolección de desechos. No obstante, el surgimiento de la bubónica vino a presionar la burocracia municipal y, en poco tiempo, demostrar la condición económica crítica en que se encontraban sus arcas.

El Consejo Superior de Higiene Pública, creado en 1892, era un órgano que entregaba recomendaciones al gobierno en el ámbito de salubridad. Para estudiar las características del brote pestoso de 1904 en Arica, envió al médico Domingo León. Una vez efectuada "la investigación bacteriolójica quedó fuera de duda la existencia de dicha enfermedad en ese puerto" (León 1904: 329). Años después, el mismo Consejo solicitó al gobierno que "arbitre los medios para mejorar las condiciones sanitarias del puerto de Arica a fin de que desaparezca el temor de que llegue a hacerse endémica una epidemia, como la bubónica" (El Ferrocarril 17 de mayo de 1911).

En este ámbito los recursos eran escasos, lo que mostraba el estado de aislamiento respecto del centro administrativo del país. Por ejemplo, en el caso del "vecino puerto de Pisagua, después que la peste bubónica hizo sus estragos en la población. Se pidió al gobierno, que se tomaran rigurosas medidas, que se concedieran fondos para exterminar la epidemia" (El Ferrocarril 7 de septiembre de 1912). Sin embargo, las dificultades burocráticas quedaron evidenciadas cuando el gobierno solicitó información al Consejo Superior de Higiene respecto del rol de la Estación Sanitaria de Arica ante un brote pestoso, "este cuerpo meramente consultivo, contestó que nada sabía de ella, pues nunca había estado bajo su dependencia la Estación. El Consejo, se ofreció para hacer las averiguaciones del caso" (Sociedad Médica de Santiago 1907: 13).

Las observaciones político-médicas describían la precaria salubridad urbana y las escasas nociones de higiene como factores que facilitaban la propagación de los contagios. En los primeros años del siglo XX se empezaron a indicar los patrones mortíferos de la afección apareciendo enfermos en distintos barrios de la ciudad, "la bubónica sienta sus bases ahí donde reina el desaseo; por consiguiente el mejor preventivo contra esta terrible enfermedad es la limpieza" (El Ferrocarril 4 de marzo de 1909). La transformación de este 
escenario, mediante la Ordenanza General de Salubridad, establecía prohibiciones a "echar las basuras a las acequias que pasen por el interior de las casas, o por las calles (...) tener cerdos dentro de las casas y en locales que disten menos de cincuenta metro de las habitaciones urbanas" (Oficina Central de Estadísticas 1896).

La mencionada Estación Sanitaria contaba con un laboratorio, lo que permitía "la observación bacteriológica de las ratas, que son los grandes conductores de la peste" (El Ferrocarril 28 de octubre de 1913). La finalidad del estudio no solo ampliaría la capacidad de los especialistas para tratar el malestar y detener el vector de contagio, también revelaría la peligrosidad del mal y tomar las medidas necesarias para su contención. Para el doctor Dávila Boza (1909: 102), resultaba clave combatir la epidemia, "sin esta acción enérjica aplicada desde el primer momento, los jérmenes del contajio se difunden en direcciones imposibles de prever; i una vez que se han constituido así focos en varios puntos de una ciudad, ya la tarea de extinguir los jérmenes es situación menos que imposible". En esa lógica, los locales públicos como el teatro local eran espacios de vigilancia para las autoridades, ya que la salud pública podía ser comprometida por la asistencia de un individuo infectado y la alta aglomeración de personas.

El lazareto era una de las instituciones públicas dedicadas al tratamiento de los enfermos, localizado en la zona periférica de la ciudad, con el propósito de mantener aislados a los individuos que portaban males infectocontagiosos. Construido en 1907, según el médico Conrado Ríos (1914: 42), estaba "compuesto por tres pabellones que tenían capacidad de 15 camas cada uno, tienen muy buena ventilación y rejillas de alambre fino, a prueba de penetración de mosquitos que puedan transmitir la fiebre amarilla". Siguiendo los preceptos de la Ley de Policía Sanitaria, cuando la familia resistía el traslado al establecimiento, se "autoriza a llevar un enfermo a la fuerza, si el dueño de casa no lo consiente no hai más que conformarse" (Archivo Histórico Vicente Dagnino, en adelante AHVD, 192, 6 de octubre de 1904, s/f).

La municipalidad desarrolló algunas ordenanzas y decretos que tenían como eje el cuidado sanitario de los habitantes. Para el cumplimiento de estas medidas, el médico de ciudad y otros funcionarios municipales realizaban inspecciones a las viviendas, los mercados y el matadero. De manera complementaria a las acciones del lazareto, los policías realizaban visitas domiciliarias dos veces a la semana. El trabajo de los funcionarios consistía en la indagación de las personas infectadas y trasladarlas a aislamiento, eso a partir de los llamados a "denunciar todo caso que se presente y que se pretenda esconder, contribuyendo a la extirpación de esta epidemia" (El Ferrocarril 18 de febrero de 1913). Por su parte, El Morro de Arica reiteraba la necesidad de que "los enfermos no sean ocultos, pues con ello solo se consigue la difusión de la epidemia" (El Morro de Arica 20 de junio de 1907). La práctica de ocultar enfermos, en gran medida se explicaba para evitar la desinfección de los hogares y el envío de las personas al temido lazareto. A su vez, tenía efectos nefastos en la propagación de la enfermedad, en la proliferación de focos sin control y en el subregistro de cifras. Asimismo, la autoridad policial entregaba órdenes vinculadas a la seguridad e higienización de la ciudad (Palma 2019: 65). En este caso la fuerza pública se preocupaba de sancionar a los habitantes que "han tornado en letrina popular el solar que existe en la calle 'Colón', antes de llegar a la de Ayacucho cuyo sitio es un verdadero foco de infección" (El Morro de Arica 29 de marzo de 1905). En esa línea, los médicos recomendaban como el mejor preservativo la clausura completa de los lugares contaminados.

\section{El trabajo médico de la enfermedad}

En esta época, el saber médico no contaba con herramientas para diagnosticar de modo preciso las afecciones, incluso los síntomas podían conducir a cuadros erróneos, obviamente, estos problemas se traspasaron a la definición de las causales de muerte (Chávez y Soto 2019: 153). Durante esos años, las desprolijidades en la determinación de los malestares y para descongestionar el servicio hospitalario ariqueño algunos enfermos eran enviados a la vecina ciudad de Tacna, uno de esos casos trasladados "con toda precipitación, y sin duda sin examen suficiente, resultó no ser de peste bubónica sino enfermo de abceso del brazo del que ha sido operado" (El Morro de Arica 20 de junio de 1907). Al llevar adelante las descripciones clínicas, los especialistas descubrieron evidencias y aumentaron sus conocimientos respecto del malestar, detectando los rasgos que permitieron caracterizarlo.

Aspectos vinculados a la práctica clínica en terreno guiaba a los especialistas a determinar la 
aparición de la enfermedad solo con la observación posterior a la muerte, al recabar información de las casas los médicos hallaron "muerta a una muchacha de corta edad, a quien se creía atacada de cólicos, por lo que no se llamó al médico, el cual al reconocer el cadáver constató, por los bubones que presentaba en las ingles, que se trataba de un caso de peste bubónica" (El Morro de Arica 25 de mayo de 1907). Luego, se procedió a desinfectar la casa y se dejó bajo vigilancia médica a los moradores. Igualmente, la historia clínica de un enfermo que situaba a su grupo familiar como sospechosos obligó a las autoridades a tomar "todas las medidas de aislamiento posibles" (AHVD, 192, 6 de octubre de 1904, s/f). El establecimientos de cuarentenas eran fundamentales para evitar la cadena de contagios y controlar los potenciales brotes epidémicos. No obstante, es preciso señalar que muchos de los casos fueron tratados en sus hogares y que los hospitales en ese momento cumplían la finalidad de reposo de los pacientes.

Las medicaciones a los contagiados, utilizadas por los médicos, principalmente constaban en la administración de suero. Esta sustancia se empleaba para mitigar los efectos de la deshidratación en el organismo. Ante el temor que provocaba el flagelo en la población, El Morro de Arica señalaba que las autoridades solicitaron "suero antibubónico a Santiago, siendo el que suministra la Sociedad Peruana de Beneficencia el que se usa en esta ciudad" (El Morro de Arica 27 de abril de 1909). En muchos sentidos, las informaciones publicadas se encontraban atravesadas por las disputas diplomáticas entre Chile y Perú. Se puede plantear que, desde la línea editorial nacionalista, se recalcaba que este medicamento se encuentra en la ciudad, pero que la municipalidad prefería solicitarlo a la capital.

En muchos casos, las intervenciones clínicas serían estériles cuando los enfermos se encontraban en condición agonizante, según la descripción del médico Conrado Ríos, "como el caso era mui grave, no quise ponerle inyección alguna de suero que no habría dado otro resultado que desacreditarlo frente al vulgo, atribuyendo la muerte a la inyección" (AHVD, 192, 14 de noviembre de 1904, s/f). Las publicaciones reiteraban las funestas consecuencias del "mal sistema que reina entre la jente del pueblo y que consiste en ocultar a los enfermos de las prescripciones médicas, fundados en que el serum y todo lo que los doctores aplican, es de funestas consecuencias para el paciente" (El Ferrocarril 10 de junio de 1913). Además, las poblaciones conformaban representaciones hacia los medicamentos, y en algunos casos, fueron resistentes a cualquier fórmula o método de laboratorio. En esta época, los vínculos entre los médicos y la población estaban marcados por la confianza de los habitantes en el curanderismo o aquellos tratamientos sustentados en la tradición.

Las políticas de higienización se apoyaban en varias ordenanzas y reglamentos legales. Como se advierte en las regulaciones, fueron trazados los problemas sanitarios en la comunidad, y lo que es más importante, las prácticas que obligaban a declarar la prohibición de "criar chanchos, vacas u otros animales, en los corrales de la parte urbana de la población" (El Morro de Arica 7 de marzo de 1908). Por lo demás, en muchas situaciones solo quedaron evidencias en el desenlace de la peste. Tal fue el caso de Florentina Miranda, quien murió violentamente en un rancho ubicado en la calle 2 de Mayo frente al "Club Arica", que se encontraba en el centro comercial de la ciudad. Inmediatamente, la autoridad sanitaria ordenó el aislamiento del rancho e "hizo conducir el cadáver al cementerio; procediéndose en seguida a hacer quemar la habitación que era formada de totora y madera vieja" (El Morro de Arica 29 de marzo de 1905).

Cuando la enfermedad se propagaba a muchas personas, el médico de ciudad se preocupaba de averiguar el origen de los focos en la ciudad, para ello debía recoger informaciones, realizar conjeturas acerca de la trayectoria de los afectados, reportarlos a la Municipalidad o bien denunciarlos a la Gobernación. Un seguimiento a varios contagiados cerca de una carnicería donde "existía hasta poco después de los primeros casos de la aparición de la peste en este puerto una crianza de conejos. Eran animales infestados por la peste dada la gran susceptibilidad de estos roedores para contraer la enfermedad" (AHVD, 192, 17 de octubre de 1904, s/f). Además, la Gobernación ordenó la destrucción de estos animales para eso se encargó a un "agente de policía que vaya formando, sin infundir sospecha y evitar una ocultación posible, una lista de aquellos vecinos que tengan tales roedores. A los que se sientan perjudicados con la medida, podrá abonársele una prima equitativa al inconveniente" (AHVD, 192, 17 de octubre de 1904, s/f). Llama la atención la publicación de recomendaciones acerca del peligro bubónico, la referencia a criar muchos más gatos y menos perros considerando que "hay 
ciertas jentes que cazan los gatos para comérselos y que habiendo perros es difícil que en las casas puedan criarse gatos aptos para la caza de ratas" (El Ferrocarril 10 de marzo de 1913).

Las panaderías, carnicerías o locales de menestras eran focos propagadores de la peste en la ciudad. Estos lugares eran los principales sospechosos al ignorarse el origen de un brote de la infección. El asombro mostrado por los doctores durante el seguimiento de casos, aumentó cuando empezaron a descubrir que en una panadería, ubicada en la calle Zapata cerca de la 2 de Mayo, se encontraba un brote asociado al recinto. Por la escasez de datos microbianos susceptibles de rendir pruebas de laboratorio y, a la vez, debido al contagio acelerado de la enfermedad, los médicos según la aparición de personas contagiadas lograban diagnosticar la trayectoria del mal. Por ejemplo, Sabina Flores "tuvo calofríos i después fiebre. Era un caso indudable de peste bubónica. Trabajaba como cocinera en la panadería" (AHVD, 192, 16 de octubre de 1904, s/f). Días más tarde fueron ingresados David Alate, Julio Clavijo y Sabina Flores, todos ellos trabajadores de la panadería y que presentaron los mismos síntomas. Esto obligó a la clausura del local "por la difusión de contajio, dada la naturaleza propia de su industria, lo que ha hecho singularmente temibles a estos focos pestosos" (AHVD, 192, 26 de octubre de 1904, s/f).

Las relaciones de los médicos con las autoridades políticas tuvo ciertas repercusiones en las decisiones adoptadas por la Gobernación. A raíz del brote de 1904, el doctor Conrado Ríos recomendaba la ejecución de cuatro preceptos para disminuir la propagación de la epidemia: " $1{ }^{\circ}$ Requisición de los enfermos; $2^{\circ}$ Desinfección de las habitaciones; $3^{\circ}$ Medidas jenerales de profilaxia i aseo; $4^{\circ}$ Evitar en cuanto sea posible que la epidemia traspase a Tacna" (AHVD, 192, 30 de septiembre de 1904, s/f). En el caso de la primera acción, la extracción de los contagiados para impedir la circulación en la comunidad y separarlo respecto de la población sana, aunque este método causaba preocupación entre los familiares por la ruptura que significaba el traslado al lazareto; la segunda, consistía en que el Oficial del Registro Civil, antes de otorgar pase al cementerio, comunicara el deceso al médico de ciudad para desinfectar la vivienda y dejar bajo vigilancia médica a las personas que convivieron con el infectado; en la tercera, se fortalecían las campañas de prensa destacando la limpieza permanente de los individuos y las viviendas; la última instrucción, transformaba a la localidad en aduana sanitaria, controlando y desinfectando las mercaderías que viajaban por ferrocarril a Tacna, además se entregaría a los pasajeros "una papeleta sanitaria en que constare que se les había sometido a la inspección médica" (AHVD, 192, 30 de septiembre de 1904, s/f).

\section{Las defunciones por la peste}

Es fundamental expresar los cambios trascendentales que se vivían en las prácticas sociales ante la muerte, el tránsito desde la administración eclesiástica de los cementerios hacia la esfera estatalcivil. Este escenario se observa en las disposiciones del Registro Civil en donde las inscripciones de defunciones estaban respaldadas, en gran medida, por la información que entregaban los familiares del difunto, según la ley "la fe de muerte será redactada por el Oficial Civil en la sección correspondiente del Rejistro Civil, después de oída la declaración de dos testigos, los cuales deberán ser parientes o vecinos del difunto" (Ley de Registro Civil N ${ }^{\circ}$ 2.184, promulgada el 16 de julio de 1884). Debido a que esta institución solo daba fe de lo aseverado por los individuos, la exigencia de este requisito fue solo para constatar un hecho por la inspección realizada al cadáver, situar el lugar en que ocurrió la muerte y haber conocido al occiso. Así, la baja calidad en las cifras se originaba porque las descripciones contaban con escaso rigor científico, porque las declaraciones solo pertenecían a familiares y, en la mayoría de los casos, no había un médico que comprobara los hechos. Así, el médico Conrado Ríos reiteraba al oficial del Registro Civil "la obligación que se le tiene impuesta de no dar pase alguno al Cementerio sin que, previamente, el infrascrito reconozca el cadáver" (AHVD, 192, 15 de octubre de 1904, s/f).

Los diagnósticos de mortandad referentes a peste bubónica también generaron controversias entre los médicos Tomás Aravena y Conrado Ríos. A partir de tres casos de peste en un hogar, había una cuarta persona que resultaba sospechosa de estar contagiada. Al llegar al domicilio el doctor Ríos se reunió con el doctor Aravena que revisó al enfermo, indicando que "era un caso de paludismo i que no había nada de bubónica. Días más tarde el enfermo seguía mal i con fiebre. Interrogué de nuevo al doctor Aravena i me respondió que había una neumonía i una infección intestinal" (AHVD, 
192, 4 de noviembre de 1904, s/f). Tras la muerte del paciente, la familia no dejó que el doctor Ríos observara el cadáver y le comunicaron que había fallecido por tuberculosis, que no había tenido hinchazones. Posteriormente, en la misma casa otro de los habitantes cayó "enfermo con fiebre, que se encontraba mal i que había solicitado médicos a Tacna" (AHVD, 192, 4 de noviembre de 1904, s/f).

La peste bubónica obligó a las autoridades médicas a establecer protocolos especiales en las inhumaciones de los fallecidos por esta causa. Las instrucciones dadas por el médico Conrado Ríos recomendaban sepultar en las afueras del cementerio, en el espacio indicado para esta clase de males y "el cadáver envuelto en una sábana empapada con sublimado al 1 x 1.000 depositando en la sepultura, antes de cerrarla una cantidad dada de cal, procedimiento que se ha seguido con todos los cadáveres de pestosos" (AHVD, 192, 26 de octubre de 1904, s/f). La cal se usaba por sus propiedades aptas para la conservación de restos en las fosas sépticas. De ese modo, los cadáveres fueron inhumados en condiciones de evitar cualquier peligro para la salubridad urbana (Del Río 1904: 44). Según el criterio médico no habían razones para instalar en la ciudad un cementerio especial para bubónicos, siendo un mal "transmisible, no contajiosa propiamente tal, salvo la forma neumónica, i para que se transmita es necesario que actúen insectos que piquen a los cadáveres. En cuanto al bacillus no podría obrar, resulta que la putrefacción en los cadáveres enterrados mata rápidamente al bacillus pestoso" (AHVD, 48, 30 de marzo de 1915, s/f).

Llama la atención los significados atribuidos a ciertas ceremonias, como los velatorios y funerales, fue uno de los tantos ejemplos que demuestran la imposibilidad de separar la ciencia de los comportamientos humanos. Las autoridades recomendaban la suspensión de los velatorios, lo que a juicio desde la esfera ilustrada representaba "agrupaciones de jente ignorante que se congregan a beber i a embriagarse al lado de cadáveres, que muchas veces no sepultan sus deudos sino más allá de los plazos reglamentarios" (AHVD, 48, 30 de marzo de 1915, s/f). En efecto, las publicaciones, basadas en la implementación de nuevos cánones salubristas y el paradigma microbiano, profundizaron la crítica a esta costumbre y recomendaban que ningún cadáver permaneciera insepulto por más de veinticuatro horas.
Finalmente, según los especialistas para el levantamiento de las medidas y la declaración de una localidad como libre de focos, debía transcurrir un plazo no inferior a quince días en que no se aparezcan casos nuevos, confirmados o sospechosos de la afección. Cuando se informó que "desde hace veinte días no se ha presentado ningún caso de peste bubónica; i de los valles, han llegado noticias mui halagadoras, respecto a la bondad de su estado sanitario" (AHVD, 192, 19 de diciembre de 1904, s/f).

\section{Conclusiones}

A inicios del siglo XX, la peste que llegó a los puertos del país fue adquiriendo el carácter endémico. Entre 1903 y 1928 los brotes de peste bubónica configuraron uno de los grandes problemas de salud pública en el puerto de Arica, desde ahí se generaron varias propuestas médicas y políticas que intentaron solucionar y mitigar los impactos de este fenómeno. El desarrollo de las enfermedades son un factor importante para el avance en las condiciones de vida de los ariqueños. Más aún, resulta evidente que las consecuencias de los progresos científicos representan claramente la época actual y que los efectos de sus aplicaciones médicas influyen profundamente en la vida cotidiana, incluso en el ámbito de las relaciones internacionales. Por consiguiente, la elevada esperanza de vida, la baja mortalidad infantil y la especialización de la farmacología, implican que las personas tienen altas posibilidades de recuperar la salud.

La relación salud-enfermedad suele variar a lo largo del tiempo producto de los factores tecnológicos, científicos y políticos. Por consiguiente, las decisiones médico-políticas radican en diversos actores durante la implementación de los tratamientos, dependiendo del enfoque para hacer frente a las enfermedades. Este razonamiento lleva a reflexionar respecto de los significados y métodos dados a cada malestar, y que, en la práctica, se manifestaron en diferentes medidas, respondiendo a la localidad afectada. La fortaleza de esta aproximación es que extiende la visión de los historiadores en la forma de convivir con las enfermedades para comprender tanto las respuestas pasadas dadas por la sociedad como su influencia en la sociedad actual.

Las enfermedades han sido un motor de evolución en la historia, en nuestro continente desde el encuentro de culturas en el siglo XVI hasta los 
profundos efectos de la mortalidad infantil, a partir de ahí las sociedades han continuado relacionándose con este vector de cambio histórico y que con frecuencia emerge provocando transformaciones radicales en la vida cotidiana. Interrogarse por la definición de las enfermedades llevó a reflexionar acerca de las continuidades en los métodos y tratamientos, a pesar de las innovaciones en el conocimiento médico. Si bien las mejoras en las infraestructuras de la ciudad y los avances en farmacéutica llevaron a una disminución progresiva de las morbilidades, actualmente la aparición de nuevas enfermedades deja a las comunidades expuestas a múltiples interrogantes e implementando métodos de contención de los contagios que tienen una larga data.

Durante las primeras décadas del siglo XX, el puerto de Arica se encontraba bajo dos procesos políticos que tuvieron profundos efectos, en primer lugar, las diferencias diplomáticas entre Chile y Perú acerca de la soberanía de Tacna y Arica, en segundo término, la puesta en práctica de la Ley de Comuna Autónoma (1891), la que otorgó amplias facultades y tareas a la administración municipal. A lo largo de estas páginas se reconoce los impactos que la peste generó en la ciudad. En efecto, analizamos factores de la marcha del control sanitario de la bubónica a nivel local y sus relaciones con las medidas impulsadas desde el gobierno central. Las decisiones para enfrentar la enfermedad fueron la consecuencia de la experiencia desplegada por los médicos de la zona, que en los períodos de brotes se preocuparon de realizar seguimientos de casos y ejecutar varias disposiciones que contribuyeron a mejorar la salubridad de la ciudad.

\section{Agradecimientos}

Al financiamiento otorgado por la Comisión Nacional de Investigación Científica y Tecnológica (CONICYT), mediante su programa formación de capital humano avanzado: Beca de Doctorado Nacional (2015). Archivo Histórico Vicente Dagnino por facilitar la revisión de documentación. A los académicos del Departamento de Ciencias Históricas y Geográficas de la Universidad de Tarapacá por fomentar y enriquecer las discusiones acerca del pasado histórico de Arica. Agradezco la dedicación de los evaluadores, sus comentarios detallados permitieron mejorar bastante el estudio.

\section{Referencias Citadas}

Armus, D.

2007 La ciudad impura. Salud, tuberculosis y cultura en Buenos Aires, 1879-1950, EDHASA, Buenos Aires, 2007. Chase, $M$.

2003 The Barbary Plague: The Black Death in Victorian San Francisco, Random House, New York, 2003.

Chávez, P. y Soto, J.

2019 "La primera estadística sanitaria infantil de la provincia de Santiago de Chile", Dynamis, vol. 39, No 1: 149-174.

Cueto, M.

2000 El regreso de las epidemias. Salud y sociedad en el Perú del siglo $X X$, Instituto de Estudios Peruanos, Lima.

Cueto, M.

2004 El valor de la salud. Historia de la Organización Panamericana de la Salud, Organización Panamericana de la Salud, Washington.

Dávila, R.

1909 "La peste bubónica en 1907", Revista Chilena de Higiene, tomo XV: 101-121.

Delgado, G., Estrella, E. y Navarro, J.

1999 "El Código Sanitario Panamericano: hacia una política de salud continental", Revista Panamericana de Salud Pública, vol. 6, No 5: 350-361.

Del Río, A., Zegers, R., Dávila, R. y Montero, L. 1904 Informe sobre la epidemia de peste bubónica en Iquique en 1903, Imprenta Cervantes, Santiago.
Díaz, A., Galdames, L. y Ruz, R.

2010 Nación e identidad en los Andes indígenas de Arica y Estado chileno (1883-1929), Ediciones Universidad de Tarapacá, Arica.

Dirección General de Estadísticas

1930 X Censo de la Población efectuado el 27 de noviembre de 1930, Imprenta Universso, Santiago.

Echenberg, $\mathrm{M}$.

2010 Plague Ports: The Global Urban Impact of Bubonic Plague, 1894-1901, NYU Press, New York.

Galdames, L. y Díaz, A.

2007 "La construcción de la identidad ariqueño-chilena durante las primeras décadas del siglo XX”, Diálogo Andino, $\mathrm{N}^{\circ} 29$ : $19-28$.

Gallinatto, V.

1930 Contribución al estudio de la epidemiología de la peste bubónica en Chile, Imprenta Cisneros, Santiago.

González, S.

1995 "El Estado chileno en Tarapacá: El claroscuro de la modernización, la chilenización y la identidad nacional", Diálogo Andino, No 13: 79-89.

Illanes, M. A.

1993 En el nombre del pueblo, del estado y de la ciencia: historia social de la salud pública, Chile, 1880-1973: hacia una historia social del Siglo XX, Colectivo de Atención Primaria, Santiago. 
Illanes, M. A.

2002 "Infección y subversión en Chile al despuntar el siglo

XX: El cuento de las ratas y de algunos animales de la selva". En Entre médicos y curanderos: cultura, historia y enfermedad en la América Latina moderna, editado por Diego Armus, pp. 151-178. Editorial Norma, Buenos Aires.

López, M. y Beltrán, M.

2013 "Chile entre pandemias: la influenza de 1918, globalización y la nueva medicina", Revista Chilena de Infectología, vol. 30, $\mathrm{N}^{\circ}$ 2: 206-215.

León, D.

1904 "Comprobación de la peste bubónica en Arica", Revista Chilena de Higiene, tomo X: 329-330.

Lo Chávez, D.

2015 "Morir en el antiguo Iquique: cementerios, salud pública y sectores populares durante la epidemia de peste bubónica de 1903", Revista Nuestro Norte: Revista del Museo Regional de Iquique, $\mathrm{N}^{\circ}$ 1: 13-37.

Márquez, J.

2001 "¿Rumores, miedo o epidemia? La peste de 1913 y 1914 en la costa atlántica de Colombia”, História, Ciências, Saúde-Manguinhos, vol. 8, № 1: 133-171.

Murillo, A.

1886 Precauciones que deben tomarse en caso de una epidemia de cólera, Imprenta de "El Progreso", Santiago.

Oficina Central de Estadísticas

1896 Anuario Estadístico de la República Chile, Imprenta Nacional, Santiago.

Palma, D.

2019 "Ladrones, policías y orden callejero en Santiago de Chile, 1896-1924", Anuario Colombiano de Historia Social y de la Cultura, vol. 46, No 2: 59-86.
Pedroso, $\mathrm{P}$.

2010 "La peste, enfermedad infectocontagiosa reemergente", Revista Cubana de Medicina General Integral, vol. 26, $\mathrm{N}^{\circ} 2: 360-375$.

Puga Borne, F.

1886 Como se evita el cólera. Estudio de hijiene popular, Imprenta Nacional, Santiago.

Ramacciotti, K.

2006 "Las sombras de la política sanitaria durante el peronismo: los brotes epidémicos en Buenos Aires", Asclepio. Revista de Historia de la Medicina y de la Ciencia, vol. 58, $\mathrm{N}^{\mathrm{o}}$ 2: 115-138.

Rebelo, F.

2013 "Entre o Carlo R. e o Orleannais: a saúde pública e a profilaxia marítima no relato de dois casos de navios de imigrantes no porto do Rio de Janeiro, 1893-1907", História, Ciências, Saúde-Manguinhos, vol. 20, № 3 : 765-796.

Ríos, C.

1914 Arica en el presente i en el porvenir, La Ilustración, Santiago.

Salinas, R.

1983 "Salud, ideología y desarrollo social en Chile 18301950", Cuadernos de Historia, $\mathrm{N}^{\circ}$ 3: 99-126.

Sociedad Médica de Santiago

1907 "Nota editorial. La peste bubónica en Arica", Revista médica de Chile, № 7: 13-14.

Zárate, $\mathrm{S}$.

2008 Dar a luz en Chile, siglo XIX. De la "ciencia de la hembra" a la ciencia obstétrica, Ediciones Universidad Alberto Hurtado, Santiago. 